MENEZES, J.B.; GOMES JUNIOR, J.; ARAÚJO NETO, S.E.; SIMÕES, A.N. Armazenamento de dois genótipos de melão amarelo sob condições ambiente. Horticultura Brasileira, Brasília, v. 19, n. 1 p. 42-49, março, 2.001.

\title{
Armazenamento de dois genótipos de melão amarelo sob condições ambiente.
}

\author{
Josivan B. Menezes; Julio Gomes Junior; Sebastião E. Araújo. Neto; Adriano do N. Simões \\ ESAM; Km 47, BR 110, Costa e Silva, C. Postal 137 59.625-900 Mossoró-RN. E-mail: quimica@esam.br
}

\begin{abstract}
RESUMO
Com o objetivo de avaliar a qualidade pós-colheita de dois genótipos de melão amarelo (TSX 32096 e SUNEX 7057) armazenados sob condições ambiente $\left(30,0 \pm 1^{\circ} \mathrm{C}\right.$ e $50,0 \pm 5 \%$ de umidade relativa), instalou-se experimento em Mossoró (RN), com frutos provenientes do Agropólo Mossoró - Assu, (RN). O clima dessa região é quente e seco, com precipitação pluviométrica de $423 \mathrm{~mm}$, temperatura máxima e mínima de 33 e $29^{\circ} \mathrm{C}$, respectivamente. O solo da área experimental é do tipo Podzólico Vermelho-Amarelo Equivalente Eutrófico. Os frutos foram colhidos nas primeiras horas da manhã no estádio de maturação comercial. Imediatamente após a colheita e seleção (frutos com boas características externas de qualidade) os melões foram embalados e transportados para o Laboratório de Análises de Frutos e Hortaliças do Departamento de Química e Tecnologia da Escola Superior de Agricultura de Mossoró, onde foram armazenados à temperatura de $30,0 \pm 1^{\circ} \mathrm{C}$ e $50,0 \pm 5 \%$ de umidade relativa por até 49 dias. As avaliações foram feitas a intervalos de 7 dias. Montouse o experimento em delineamento inteiramente casualizado em esquema fatorial do tipo 2 × 8 (genótipos $\mathrm{x}$ tempo de armazenamento) com 3 repetições, cada parcela composta por 3 frutos. Foram avaliadas as seguintes características: firmeza da polpa, perda de peso, aparência (externa e interna), acidez total titulável, $\mathrm{pH}$, o conteúdo de sólidos solúveis totais, vitamina $\mathrm{C}$ total e os açúcares solúveis (redutores, não-redutores e totais). Houve interação significativa entre os fatores estudados (temperatura $\mathrm{x}$ tempo de armazenamento) para a firmeza da polpa, aparência interna e teor de açúcares solúveis (redutores, não-redutores e totais). Os resultados revelam aumento regular na perda de peso e um declínio na firmeza da polpa durante o período experimental. Os dois genótipos apresentaram redução na firmeza da polpa e da qualidade externa e interna até o final do período experimental, no entanto, o genótipo TSX 32096 apresentou uma firmeza de polpa mais elevada e uma melhor aparência interna. A firmeza da polpa aos 42 dias de armazenamento foi de $18,40 \mathrm{~N}$ e $15,38 \mathrm{~N}$ para os genótipos TSX 32096 e SUNEX 7057, nesta ordem. A perda de peso aos 42 e 49 dias de armazenamento foi de $4,60 \%$ e $5,12 \%$, respectivamente. Houve redução da acidez total titulável, do conteúdo de sólidos solúveis totais e da vitamina $\mathrm{C}$ total para os dois genótipos. $\mathrm{O}$ conteúdo de açúcares totais sofreu um acréscimo (variação de 6,8\% para $8,2 \%$ ) e um declínio (variação de $9,5 \%$ para $8,8 \%$ ) durante o armazenamento, para os genótipos TSX 32096 e SUNEX 7057, nesta ordem. De acordo com os dados, os genótipos TSX 32096 e SUNEX 7057 apresentaram uma vida útil pós-colheita de 42 dias sob condições ambiente $\left(30,0 \pm 1^{\circ} \mathrm{C}\right.$ e $50,0 \pm 5 \%$ de umidade relativa).
\end{abstract}

Palavras-chave: Cucumis melo L., armazenamento, qualidade.

\section{ABSTRACT}

Storage of yellow melons, genotypes TSX 32096 and SUNEX 7057, at room temperature.

The purpose of this research was to examine the postharvest quality of two yellow melon genotypes TSX 32096 and SUNEX 7057, at room temperature $\left(30,0 \pm 1{ }^{\circ} \mathrm{C}\right.$ and at relative humidity of $\left.50,0 \pm 5 \%\right)$. The experiment was carried out in Mossoró, Brazil, with fruits produced at Pólo Agrícola Mossoró-Assu. The region is characterized by hot dry summer with maximum and minimum temperature of $33^{\circ} \mathrm{C}$ and $29^{\circ} \mathrm{C}$, respectively. Fruits were harvested at the stage of commercial maturity. Immediately after harvesting and selection (fruits presenting good external characteristics of quality) were transported to Mossoró and were stored during 49 days. The analyses were conducted at sevenday-intervals. A 2 x 8 factorial in completely randomized design with three replications was used. The factorial consisted of two genotypes (TSX 32096 and SUNEX 7057) and eight storage periods (0, 7, 14, $21,28,35,42$ and 49 days). The following traits were evaluated during this period: pulp firmness, weight loss, external and internal aspect, titratable acidity, $\mathrm{pH}$, soluble solids contents, total vitamin $\mathrm{C}$ and soluble sugars (reducing, non-reducing and totals). A significant interaction was observed among the factors cultivars $\mathrm{x}$ time during storage for pulp firmness, internal aspect and soluble sugars (reducing, nonreducing and totals). The results of this study showed regular increase of weight loss and decline of pulp firmness during storage. The firmness of the pulp tissue and external and internal quality declined during storage for two cultivars, however, the cultivar TSX 32096 showed a significantly higher pulp firmness and better internal aspect. The values for pulp firmness at 42 days of storage was 18,40 $\mathrm{N}$ and 15,38 $\mathrm{N}$ for cultivars TSX 32096 and SUNEX 7057, respectively. The weight loss observed at 42 and 49 days of storage was $4,60 \%$ and 5,12\% for the two cultivars. A decline of titratable acidity, soluble solids contents and total vitamin $\mathrm{C}$ for two cultivars was observed. The total sugars increased $(6,8 \%$ to $8,2 \%)$ and decline $(9,5 \%$ to $8,8 \%)$ during fruits storage of cultivars TSX 32096 and SUNEX 7057, respectively. Fruits of TSX 32096 and SUNEX 7057 melon presented 42 days of shelf life $\left(30,0 \pm 1{ }^{\circ} \mathrm{C}\right.$ and at relative humidity of $\left.50,0 \pm 5 \%\right)$.

Keywords: Cucumis melo L., storage, quality.

(Aceito para publicação em 01 de dezembro de 2.000).

$\mathrm{O}$ melão (Cucumis melo L.) é derivado de formas nativas encontradas na Índia (Salunke \& Desai, 1984). Apresenta plantas anuais, herbáceas, caule prostrado, com número de hastes e ramificações variáveis em função da cultivar (Pedrosa, 1997). Os frutos cultivados apresentam considerável varia- ção de tamanho, forma e peso; a casca pode apresentar-se lisa, enrugada, tipo "rede" ou em forma de gomos. Os frutos imaturos são normalmente verdes e 
quando maduros mudam para amarelo, dependendo da cultivar. É uma das espécies olerícolas de maior expressão econômica e social para a região Nordeste do Brasil, gerando cerca de 20.000 a 30.000 empregos diretos, sem contar com aqueles relacionados com o transporte, comercialização e venda de insumos (Pedrosa, 1997).

Esse interesse tem sido estimulado pela crescente exportação e condições ótimas de clima para o desenvolvimento dessa cultura. A alta luminosidade, os baixos índices pluviométricos (com exceção do período de janeiro a maio que é a estação chuvosa) e a baixa umidade relativa do ar, além da inexistência da mosca-das-frutas, permitem uma produção durante quase todo o ano.

No Brasil, a produção de melão concentra-se na região Nordeste de modo especial nos Estados de Pernambuco, Bahia, Paraíba, Ceará e Rio Grande do Norte, onde $90 \%$ da área total plantada é responsável por cerca de $91 \%$ da produção nacional (Dias et al. 1998). Em 1998 as 58.900 toneladas exportadas deram ao Estado do Rio Grande do Norte o título de líder nacional, com $91 \%$ de participação no mercado, com um aumento de $34,2 \%$ em volume com relação a 1996.

A qualidade de um produto agrícola (fruto ou hortaliça) pode ser definida através de critérios de qualidade. Estes incluem propriedades nutricionais (vitaminas, proteínas, carboidratos etc.), higiênicas (condição microbiológica, conteúdo de componentes tóxicos, etc.), tecnológicas (capacidade de armazenamento) e sensoriais (aparência, aroma, textura etc.). Quando se conhece o critério que caracteriza a qualidade de um produto utiliza-se métodos de mensuração que variam desde técnicas instrumentais avançadas até análise sensorial (Menezes, 1996).

Em melão, o termo qualidade na précolheita tem sido relacionado a diferentes características, sendo as mais estudadas a firmeza da polpa, o conteúdo de sólidos solúveis totais (SST), a avaliação subjetiva relacionada à aparência (externa e interna), o conteúdo de açúcares solúveis (redutores, não-redutores e totais), bem como, a perda de peso e o valor nutricional (conteúdo vitamínico).
O conteúdo de SST, definido como a percentagem de sólidos solúveis no suco extraído da polpa, é um fator tradicionalmente usado para assegurar a qualidade do melão, embora em alguns casos seja considerado como um indicador de qualidade falho (Menezes et al., 1998b). A importância do SST na qualidade dos frutos é relatada por Cohen \& Hicks (1986), que comprovaram uma forte correlação entre o SST e a aceitação, doçura e aroma.

Yamaguchi et al. (1977), em estudo sobre a correlação entre análise sensorial e SST em cantaloupe, determinaram outros atributos de qualidade, tais como: firmeza da polpa, aparência (interna e externa) e compostos voláteis.

A firmeza da polpa é um dos principais atributos de qualidade em frutos. Suas propriedades mecânicas de resistência dos tecidos se correlacionam com as características estruturais do conglomerado celular, sendo também um dos recursos mais utilizados no acompanhamento do amolecimento dos frutos, uma vez que sofre alterações durante este processo (Tucker, 1993), sendo uma ocorrência importante no armazenamento de frutos e hortaliças. Dos atributos de qualidade, a textura se caracteriza como um dos mais importantes, constituindo-se, portanto, em um dos desafios da fisiologia pós-colheita para manutenção da integridade dos frutos. Sob o ponto de vista de manuseio pós-colheita, a textura é essencial, em razão de frutos com maior firmeza serem mais resistentes às injúrias mecânicas durante o transporte e comercialização (Grangeiro, 1997). Mutton et al. (1981) concluíram, a partir de modelos matemáticos que o nível mínimo sugerido para a firmeza da polpa por ocasião da colheita dos melões 'PMR 45', 'Goldpack' e 'Gulfstream' deve estar entre 9,80 N e 19,60 N.

A vitamina $C$ é muito encontrada no reino vegetal e recebe o nome de ácido ascórbico, forma principal de atividade biológica. Ao se oxidar, o ácido ascórbico transforma-se em ácido dehidroascórbico, que também possui atividade de vitamina C. O requerimento diário do homem em vitamina $\mathrm{C}$ se encontra na faixa de $50 \mathrm{mg}$. O conteúdo de vitamina $\mathrm{C}$ total em melão é relati- vamente baixo quando comparado com outras culturas como o caju, abacaxi, manga e acerola. Os frutos constituem a fonte natural mais importante de vitamina C (ácido ascórbico) para os seres humanos, e os que se destacam pelo alto conteúdo desse ácido são: acerola, caju, mamão, goiaba, citrus, morango, manga, caqui, kiwi, maracujá e tomate (Awad, 1993). Evensen (1983) considerou o conteúdo de ácido ascórbico um importante fator de qualidade para as cultivares Superstar, Classic, Roadside, Star Headliner, Star Trek e Harvest Pride durante o armazenamento. Dhiman et al. (1995) reportaram que o teor de ácido ascórbico pode ser usado como forma de avaliar a qualidade de diferentes cultivares de melão. Kader (1992), Salunke \& Desay (1984) e Cohen \& Hicks (1986) levaram em consideração critérios visuais, organolépticos, texturais e nutritivos. Artés et al. (1993) ampliaram os critérios de qualidade para o melão, estudando peso, tamanho, forma, espessura da casca, proporção da porção comestível, firmeza, SST, pH, acidez total titulável, açúcares redutores e não-redutores, além do índice de formol, nutrientes minerais e velocidade de respiração.

Como o consumidor não pode julgar com confiabilidade a qualidade do melão (conteúdo de açúcar) pela aparência externa, há necessidade de se introduzir padrões de mercado que servem para prevenir a venda de frutos de baixa qualidade. Isso indica que há inúmeros fatores relacionados com a qualidade pós-colheita do melão, e que o não entendimento por parte dos produtores poderá desvalorizar substancialmente o produto a nível de consumidor.

Na região Nordeste há predomínio do cultivo de melão do grupo inodorus, devido ao seu maior potencial de conservação pós-colheita (25 a 30 dias) em relação às cultivares dos grupos reticulatos e cantaloupe (Souza et al., 1994), as duas últimas não alcançando quatorze dias de vida útil pós-colheita sob condições ambiente. Diversos genótipos estão sendo plantados no Rio Grande do Norte, dentre eles, o 'Gold Mine', 'AF 646', 'AF 682' e 'Piel de Sapo', todos pertencentes ao grupo inodorus. Anualmente, verifica-se a introdução de diversos genótipos de melão com o objetivo de diversificar o pro- 
duto a ser oferecido aos mercados interno e externo. O conhecimento sobre o comportamento pós-colheita desses novos materiais é fundamental para que o produtor possa decidir sobre a sua introdução em plantios comerciais, haja visto que os principais mercados consumidores (Região Sudeste do Brasil e Europa) necessitam que o produto apresente bom potencial de conservação póscolheita.

A importância econômica da cultura tem estimulado a intensificação das pesquisas nos últimos anos sobre fisiologia, bioquímica e tecnologia pós-colheita do fruto (Menezes et al., 1997).

O presente trabalho objetivou avaliar o potencial de conservação pós-colheita dos genótipos TSX 32096 e SUNEX 7057 armazenados à temperatura de $30,0 \pm 1^{\circ} \mathrm{C}$ e umidade relativa de $50,0 \pm$ $5 \%$, através de características representativas de qualidade.

\section{MATERIAL E MÉTODOS}

Os frutos foram obtidos de plantio comercial localizado no Agropólo Mossoró-Assu, (RN). O clima dessa região é quente e seco, com precipitação pluviométrica de $423 \mathrm{~mm}$, temperatura máxima e mínima de 33 e $29^{\circ} \mathrm{C}$, respectivamente. $\mathrm{O}$ solo da área experimental é do tipo Podzólico VermelhoAmarelo Equivalente Eutrófico. Colheu-se os frutos no estádio de maturação comercial, adotando-se como critério para a colheita um conteúdo mínimo de sólidos solúveis totais (SST) de $8,0 \%$ e boas características visuais (externa e internamente). Em seguida, os frutos foram conduzidos ao Laboratório de Pós-colheita de Frutos e Hortaliças do Departamento de Química e Tecnologia da ESAM, onde foram pesados, selecionados (eliminando-se os frutos portadores de imperfeições) e armazenados em uma sala com ar condicionado à temperatura de $30,0 \pm 1^{\circ} \mathrm{C}$ e umidade relativa de $50,0 \pm 5 \%$ por até 49 dias.

As avaliações foram realizadas em intervalos regulares de sete dias. A perda de peso foi determinada em relação ao peso inicial dos frutos $(1.997 \mathrm{~g} \mathrm{e}$ 1.821g para os genótipos TSX 32096 e SUNEX 7057, respectivamente) por ocasião da colheita e àqueles obtidos em cada intervalo de amostragem. Os resultados foram expressos em percentagem (\%). Para a avaliação da firmeza da polpa, o fruto foi dividido longitudinalmente em duas partes, sendo que em cada uma das metades procedeu-se duas leituras na polpa (em regiões opostas) com penetrômetro de marca $\mathrm{Mc}$ Cormick modelo FT 327 com ponteira de $8 \mathrm{~mm}$ de diâmetro. Os resultados obtidos em libras (lbf) foram transformados para Newton $(\mathrm{N})$ utilizando-se o fator de conversão 4,45.

A avaliação da aparência externa e interna foi realizada utilizando-se uma escala visual e subjetiva. A escala corresponde a notas variando de 1 a 5 , atribuídas por três pessoas treinadas, de acordo com a severidade dos defeitos (nota $1=$ defeitos extremamente severos em mais de $50 \%$ da área do fruto; nota 2 $=$ defeitos severos em 31 a 50\% da área do fruto; nota $3=$ defeitos moderados em 11 a $30 \%$ da área do fruto; nota $4=$ defeitos leves em 1 a $10 \%$ da área do fruto e, nota 5 = ausência de defeitos). Considerou-se como fruto inadequado para a comercialização aquele cuja nota apresentou valor igual ou inferior a 3,0 para quaisquer das avaliações.

A acidez total titulável (ATT) foi determinada em duplicata utilizando-se uma alíquota de $25 \mathrm{ml}$ de suco, ao qual adicionou-se $75 \mathrm{ml}$ de água destilada e 5 gotas de fenolftaleína alcoólica a $1,0 \%$. A seguir procedeu-se a titulação até o ponto de viragem com solução de $\mathrm{NaOH}$ a $0,1 \mathrm{M}$, previamente padronizada. Os resultados foram expressos em percentagem de ácido cítrico, conforme metodologia proposta por Artés et al.(1993). O potencial hidrogeniônico $(\mathrm{pH})$ foi determinado no suco em duplicata, utilizando-se um potenciômetro digital modelo DMPH-2 Digimed.

O conteúdo de sólidos solúveis totais foi determinado no suco, após homogeneização da polpa em liqüidificador doméstico e posterior filtração, por refratometria utilizando-se um refratômetro digital modelo PR-100 Palette (Attago Co., Ltd, Japan). Os resultados foram expressos em percentagem, conforme metodologia proposta por Kramer (1973). O conteúdo de vitamina $\mathrm{C}$ total foi determinada através da titulação com iodato de potássio e os resultados expressos em $\mathrm{mg} / 100 \mathrm{~mL}$ de suco, conforme metodologia proposta pelo Instituto Adolfo Lutz (1985).

As determinações dos açúcares solúveis totais extraídos do suco foram realizadas com o suco tendo sido mantido em freezer por um período máximo de 24 horas sendo os açúcares redutores e não redutores analisados pelo método de Somoghy-Nelson (Southgate, 1991). Os resultados foram expressos em percentagem.

O delineamento experimental foi inteiramente casualizado, em esquema fatorial $2 \times 8$, onde o primeiro fator referiu-se aos genótipos (TSX 32096 e SUNEX 7057) e, o segundo, aos intervalos de armazenamento $(0,7,14,21$, $28,35,42$ e 49 dias). Foram utilizadas três repetições com três frutos por parcela, totalizando cento e quarenta e quatro frutos no experimento. Os resultados foram submetidos à análise de variância através do software SPSSPC (Norusis, 1990) e detectada interação significativa procedeu-se a regressão polinomial através do software Table Curve (Jandel Scientific, 1991).

\section{RESULTADOS E DISCUSSÃO}

Houve efeito significativo da interação $(\mathrm{p}<0,05)$ para as variáveis firmeza da polpa, aparência interna e açúcares solúveis (redutores, não-redutores e totais).

Observou-se um decréscimo linear acentuado na firmeza da polpa para os dois genótipos (Figura 1). O genótipo TSX 32096 foi o que apresentou maior firmeza da polpa ao longo de todo período experimental, com uma firmeza média de $24,14 \mathrm{~N}$, sendo $29 \%$ superior à firmeza do SUNEX 7057. A firmeza inicial foi de 32,18 amaciando acentuadamente para $16,08 \mathrm{~N}$, correspondendo a uma redução de $53 \%$ na sua firmeza. O genótipo SUNEX 7057 teve uma firmeza média de $18,72 \mathrm{~N}$ sofrendo uma redução de $40 \%(23,39 \mathrm{~N}$ a $14,04 \mathrm{~N})$, do início ao final do período experimental, nesta ordem. A menor firmeza da polpa proporcionada pelo SUNEX 7057 foi provavelmente devido à características do ponto de colheita já que o TSX 32096 foi colhido num estádio em que a cor da casca se apresentava amarelo-verdosa, 
enquanto que o SUNEX 7057 foi colhido no estádio amarelo. Segundo Tucker (1993), a perda de turgor (desidratação dos tecidos) é um dos fatores responsáveis pelo amolecimento. Além disso a água ajuda a manter a estabillidade estrutural da parede celular (Bartley \& Knee, 1982), sendo possível que a exposição dos frutos a uma temperatura mais elevada possa ter contribuído para uma ação mais intensa das enzimas envolvidas no amadurecimento.

Essa redução na firmeza da polpa é uma característica geral do processo de amadurecimento em diversos frutos, inclusive melão, e também foi observado por Miccolis \& Saltveit Jr (1991) em sete cultivares do mesmo grupo (inodorus). Neste experimento a firmeza da polpa reduziu-se para valores inferiores a $50 \mathrm{~N}, 60$ dias após a antese. Lester \& Shellie (1992) também observaram uma redução acentuada na firmeza da polpa de melões "Honey Dew" após 10 dias de armazenamento a $18^{\circ} \mathrm{C}$. Miccolis \& Saltveit (1995) observaram que após três semanas de armazenamento refrigerado $(7,12 \mathrm{e}$ $15^{\circ} \mathrm{C} ; \mathrm{UR}=90 \%$ ) frutos das cvs. Honeydew, Amarelo, Juan Canary e Golden Casaba apresentaram redução na firmeza da polpa de 67, 63, 60 e 54\%, respectivamente. Entretanto, nas cvs. Pacceco e Honey Loupe esta redução foi de apenas $40 \%$ e $32 \%$, nesta ordem.

Verificou-se um comportamento linear crescente na perda de peso ao longo do tempo de armazenamento; no entanto, a interação entre os fatores genótipos $\mathrm{x}$ tempo de armazenamento não foi significativa (Figura 1). Avaliando os coeficientes de correlação entre a perda de peso e a firmeza da polpa, percebe-se uma relação inversa, indicando que a perda de peso pode influenciar na redução da firmeza da polpa. A perda de peso atingiu valores médios de 3,30\%

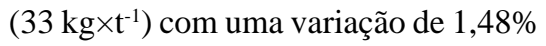
$\left(14,8{\left.\mathrm{~kg} \times \mathrm{t}^{-1}\right)}^{-1}\right.$ para $5,12 \%\left(51,2 \mathrm{kg \times t^{-1 }}\right)$ no início e aos 49 dias de armazenamento. Essa perda de peso pode ser atribuída principalmente à perda de umidade (evapotranspiração) e ao consumo de açúcares (respiração). No entanto, nesse experimento acredita-se que a perda de peso tenha sido ocasionada principalmente pelo primeiro fa-

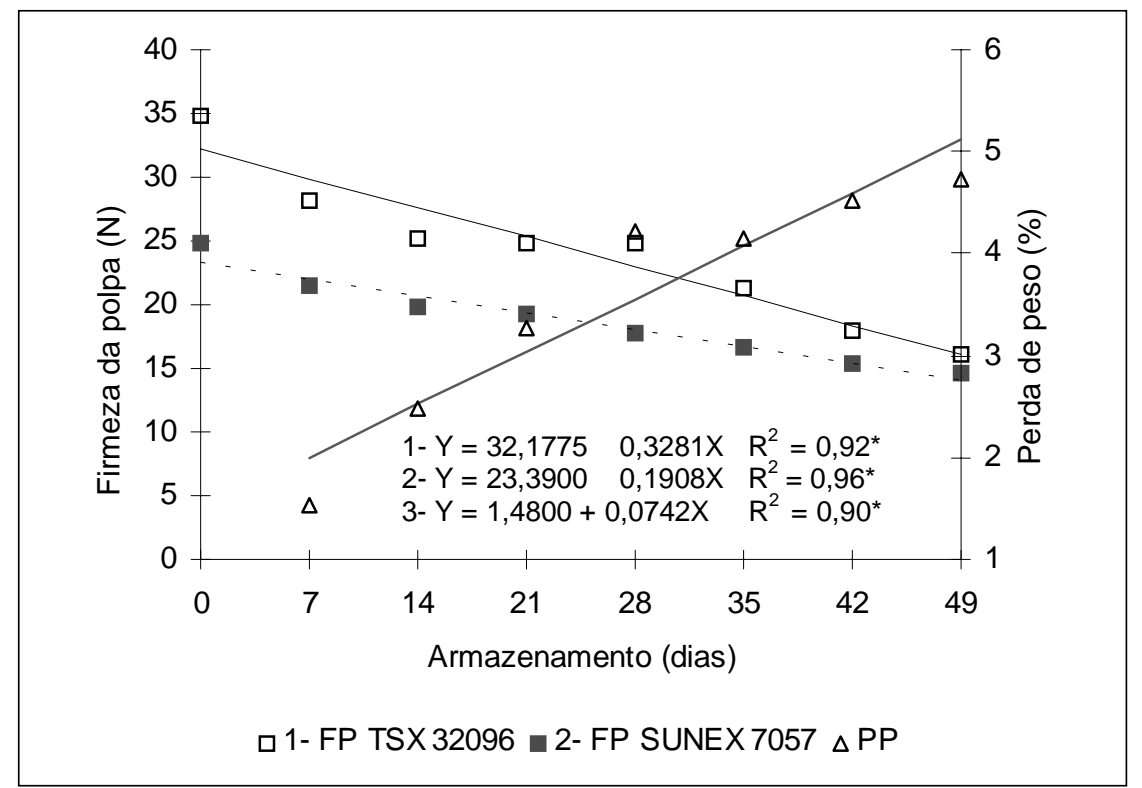

Figura 1. Efeito da duração do armazenamento em condições ambiente $\left(\mathrm{T}=30,0 \pm 1^{\circ} \mathrm{C}\right.$ e $\mathrm{UR}=50,0 \pm 5 \%$ ) sobre a firmeza da polpa (FP) e perda de peso (PP) de melão amarelo, genótipos TSX 32096 e SUNEX 7057. Mossoró, ESAM, 1998.

tor (no caso do TSX 32096) e pelo segundo fator (no caso do SUNEX 7057) como pode ser notado na Figura 5. Os açucares solúveis totais tiveram um comportamento crescente e decrescente ao longo do armazenamento para os dois genótipos mencionados, nesta ordem. Os resultados obtidos neste trabalho são semelhantes àqueles obtidos por Menezes et al. (1995), em pesquisa realizada com o genótipo AF 646, em que a perda de peso atingiu valores médios de $3,60 \%$ e $6,70 \%$, aos 25 e 45 dias de armazenamento, respectivamente. Segundo Kader (1992) a perda de peso é a causa principal de deterioração no armazenamento, resultando não apenas em uma perda quantitativa (perda de peso), o que ocasiona sérios prejuízos econômicos (normalmente os frutos são vendidos por unidade de peso), mas também em uma perda qualitativa (enrugamento, amolecimento, etc.). No entanto, a perda de peso de até $4,60 \%$ não foi suficiente para causar alguma perda na qualidade comercial dos frutos até o período de 42 dias (tempo de vida útil), a partir do qual os frutos de ambos genótipos foram afetados qualitativamente no que se refere a sua aparência externa e interna. Esses resultados são concordantes com os trabalho realizados por Gonçalves et al., (1996), em que reduções em torno de $5 \%$ no peso dos frutos de melão, não foi suficiente para causar enrugamento da casca ou afetar significativamente a aparência externa dos frutos até 45 dias de armazenamento.

O comportamento da avaliação subjetiva (aparência externa e interna) pode ser visto na Figura 2. As principais características que conferiram perda da qualidade externa dos frutos foram o murchamento, o surgimento de manchas escuras devido à senescência e a fermentação, sendo mais aparentes a partir dos 42 dias de armazenamento. Miccolis \& Saltveit Jr (1995) também verificaram aumento progressivo de manchas superficiais em frutos de melão armazenado a $7^{\circ} \mathrm{C}$ e umidade relativa próxima de $90 \%$. No presente trabalho, os dois genótipos apresentaram-se com boa qualidade externa até 42 dias de armazenamento, quando então começaram a surgir alguns sinais de senescência. Os genótipos alcançaram o $42^{\circ}$ dia de armazenamento com nota média de 4,0 (parte do fruto afetada em 1 a 10\%) para a aparência externa e interna. $\mathrm{O}$ comportamento em relação a perda da qualidade externa foi idêntico para ambos os genótipos. No que se refere à aparência interna, o genótipo SUNEX 7057 foi o mais afetado com o colapso interno da polpa já que aos 42 dias de armazenamento teve nota mé- 


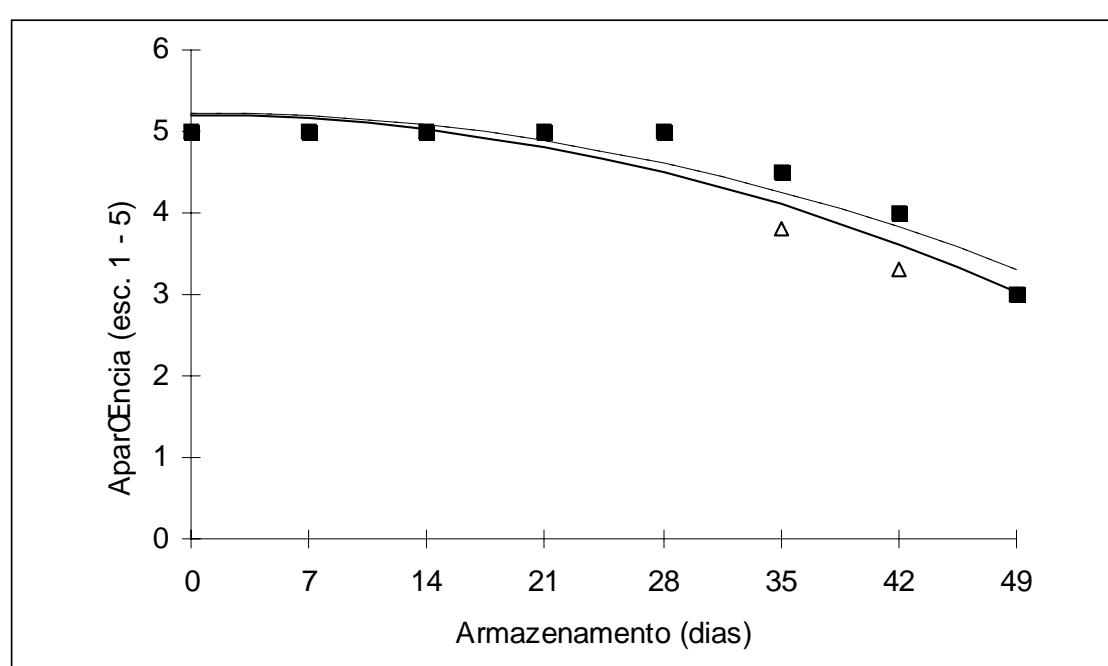

口1- AE TSX 32096 e SUNEX 7057 - 2- AI TSX $32096 \Delta 3$ AI SUNEX 7057

Figura 2. Efeito da duração do armazenamento em condições ambiente $\left(\mathrm{T}=30,0 \pm 1^{\circ} \mathrm{C}\right.$ e $\mathrm{UR}=50,0 \pm 5 \%$ ) sobre a aparência externa (AE) e aparência interna ( $\mathrm{AI})$ de melão amarelo, genótipos TSX 32096 e SUNEX 7057. Mossoró, ESAM, 1998.

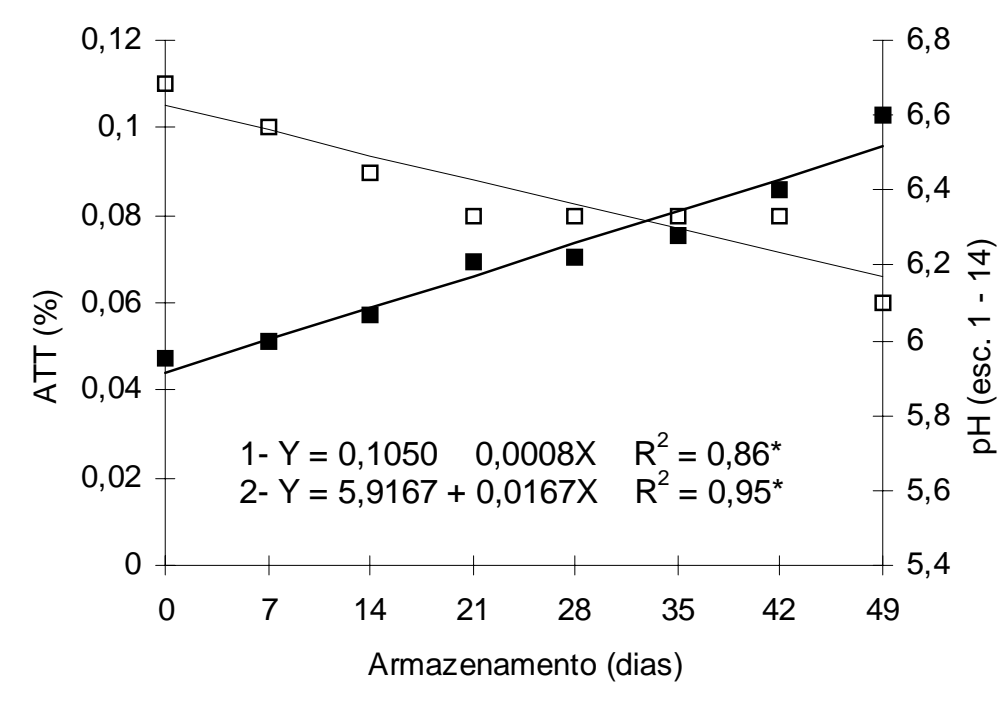

$\square \mathrm{ATT} \backsim \mathrm{pH}$

Figura 3. Efeito da duração do armazenamento em condições ambiente $\left(\mathrm{T}=30,0 \pm 1^{\circ} \mathrm{C}\right.$ e $\mathrm{UR}=50,0 \pm 5 \%$ ) sobre a acidez total titulável (ATT) e o potencial hidrogeniônico $(\mathrm{pH})$ de melão amarelo, genótipos TSX 32096 e SUNEX 7057. Mossoró, ESAM, 1998.

dia de 3,3 (parte do fruto afetada em 11 a 30\%), enquanto que o TSX 32096 alcançou esse mesmo período com nota média de 4,0 (parte do fruto afetada em 1 a $10 \%)$. Considerando que os frutos com nota menor ou igual a 3,0 eram inadequados ao consumo, conclui-se que a vida útil pós-colheita dos melões amarelos, genótipos TSX 32096 e SUNEX 7057, limita-se a 42 dias sob condições ambiente $\left(30,0 \pm 1^{\circ} \mathrm{C}\right.$ e umidade relativa de 50,0 $\pm 5 \%$ ). Estes dados são extremamente úteis na estimativa dos limites de tempo de comercialização para o produto.

Não houve interação significativa entre os fatores genótipos e tempo de armazenamento (Figura 3) para as variáveis acidez total titulável (ATT) e $\mathrm{pH}$. Como pode ser observado na Figura 3, a acidez decresceu linearmente até o fi- nal do período experimental, concordando com a elevação no $\mathrm{pH}$, que sofreu um acréscimo ao longo do armazenamento. Os resultados mostraram que os dois genótipos tiveram comportamento semelhante durante todo o período experimental para essas duas variáveis. Os valores médios para a ATT no início e aos 49 dias de armazenamento foram de $0,11 \%$ e 0,07\% de ácido cítrico, respectivamente. Essa redução pode ser atribuída à utilização desse ácido no processo respiratório (Campbell, Huber \& Koch, 1989). Esses resultados estão de acordo com os obtidos por Menezes et al., (1995) e Gonçalves et al., (1996) para os genótipos AF 646 e Piel de Sapo armazenados sob refrigeração. Esses autores reportaram uma variação de $0,15 \%$ a $0,10 \%$ e de $0,19 \%$ a $0,13 \%$ para o $\mathrm{AF}$ 646 e Piel de Sapo, nesta ordem, do início ao final do período experimental. Carvalho (1995) reportou um comportamento constante da ATT em melão Yellow King até 21 dias de armazenamento a $25 \pm 2^{\circ} \mathrm{C}$ e $70 \pm 5 \%$ de umidade relativa, observando uma redução a partir desse período. O conteúdo médio foi de $0,14 \%$. Por ocasião da colheita os frutos apresentaram um pH médio de 5,92 aumentando para 6,51 aos 49 dias de armazenamento. Aos 42 dias (tempo de vida útil dos genótipos) o pH médio ficou em torno de 6,43. Esse aumento no $\mathrm{pH}$ pode ser explicado pelo consumo de ácidos orgânicos durante a respiração. Esses resultados estão de acordo com os obtidos por Silva (1993) para os genótipos Gold Mine e Duna sob condições ambiente $\left(26,0 \pm 2^{\circ} \mathrm{C}\right.$ e 65,0 $\pm 2 \%$ de umidade relativa). Esse autor relatou uma variação no $\mathrm{pH}$ de 5,47 para 6,17 e 5,55 para 6,05 , no início e no final do período experimental, para os genótipos Gold Mine e Duna, nesta ordem. Apesar da facilidade na metodologia de análise para a determinação da ATT e do pH, Menezes et al. (1998b) citam que a variação nos níveis da ATT durante a maturação do melão têm pouco significado prático em função da baixa concentração. Assim, o conteúdo de ácidos orgânicos apresenta pouca contribuição para o sabor e aroma, o que justifica a ausência de estudos sobre o metabolismo dos ácidos durante a maturação do melão e armazenamento. 
Observou-se um comportamento linear e decrescente para o conteúdo de SST e vitamina C total (Figura 4). A determinação do conteúdo de sólidos solúveis, normalmente é feita com o objetivo de se ter uma estimativa da quantidade de açúcares presentes nos frutos, embora, medidos através de um refratômetro, incluem, além dos açúcares solúveis, pectinas, vitaminas hidrossolúveis, sais e ácidos orgânicos. O conteúdo de sólidos solúveis tem sido usado como um indicador de maturação e critério de aceitação comercial, no entanto, a doçura, o sabor o aroma e a firmeza da polpa, são fatores de qualidade complementar. $\mathrm{O}$ conteúdo médio de SST foi de $11,5 \%$, com uma variação de $12,4 \%$ (por ocasião da colheita) para $10,6 \%$ no final do período experimental. Aos 42 dias de armazenamento os frutos apresentaram um conteúdo médio de 10,8\%. Menezes et al., (1998a) reportaram conteúdos médios de SST entre $9 \%$ e $10 \%$ para os genótipos Gold Mine e AF 646. Segundo esses mesmos autores um conteúdo médio de SST superior a $9 \%$ é bastante desejável sob o ponto de vista comercial, em virtude do SST ser um importante fator de qualidade em muitos países, inclusive no Brasil. Os valores encontrados para o SST estão bem acima do exigido para o mercado americano e europeu que é de $9 \%$ e $8 \%$, respectivamente. O elevado conteúdo de SST pode ter contribuído para a fermentação alcoólica que ocorreu após esse tempo de armazenamento o que contribuiu para limitar a vida útil em 42 dias, no máximo, sob condições ambiente para os dois genótipos. A alta concentração de substâncias alcoólicas é encontrada, principalmente, nos tecidos mais internos que amolecem e subseqüentemente degradam (Motomura, 1994). Alta concentração de substâncias alcoólicas (acima de $100 \mathrm{~mL} \cdot 100 \mathrm{~mL}^{-1}$ de suco) causa um aroma desagradável e diminui a qualidade organoléptica e comercial do produto. O conteúdo de vitamina $\mathrm{C}$ total (ácido ascórbico + ácido dehidroascórbico) foi afetado significativamente pelo tempo de armazenamento, havendo oxidação desses componentes durante o período experimental (Figura 4). A redução foi da ordem de $80 \%$ até 49 dias de armazenamento. $\mathrm{O}$ conteúdo médio foi

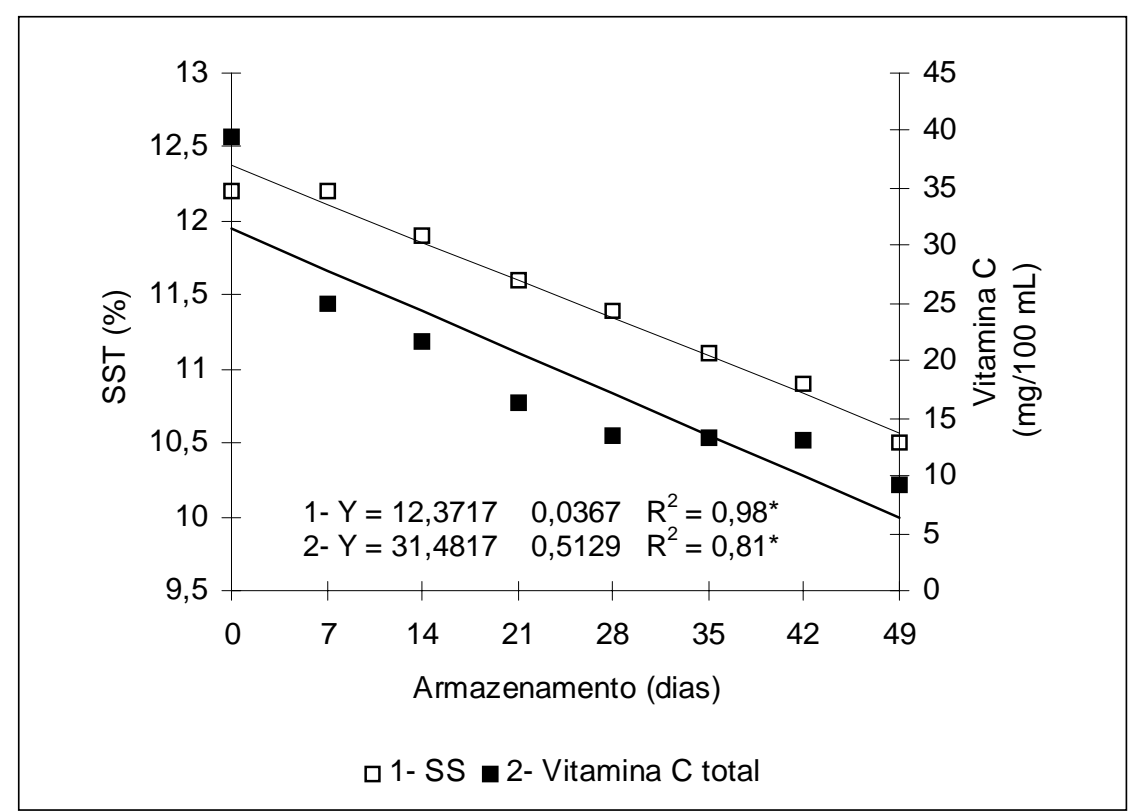

Figura 4. Efeito da duração do armazenamento em condições ambiente $\left(\mathrm{T}=30,0 \pm 1^{\circ} \mathrm{C}\right.$ e $\mathrm{UR}=50,0 \pm 5 \%$ ) sobre os sólidos solúveis totais (SST) e a vitamina C de melão amarelo, genótipos TSX 32096 e SUNEX 7057. Mossoró, ESAM, 1998.

de $18,92 \mathrm{mg} 100 \mathrm{~mL}^{-1}$ com uma variação de $31,48 \mathrm{mg} 100 \mathrm{~mL}^{-1}$ (por ocasião da colheita) para $6,35 \mathrm{mg} 100 \mathrm{~mL}^{-1}$ (no final do experimento). Aos 42 dias o conteúdo médio foi $9,94 \mathrm{mg} 100 \mathrm{~mL}^{-1}$. $\mathrm{O}$ conteúdo de vitamina $\mathrm{C}$ total em melão é relativamente baixo quando comparado com outras culturas como o caju, abacaxi, manga e acerola. Dhiman et al. (1995) analisando o teor vitamínico de quatro cultivares de melão encontraram variações de $24,90 \mathrm{mg} \cdot 100 \mathrm{~mL}^{-1}$ a 32,49 mg. $100 \mathrm{~mL}^{-1}$. O conteúdo médio foi de 32,$49 ; 27,73 ; 28,50$ e $24,90 \mathrm{mg} \times 100 \mathrm{~mL}^{-1}$, respectivamente para as cultivares MR12, Hara Madhu, Punjab Sunehri e Punjab. Eitenmiller (1987) encontrou valores médios de $28 \mathrm{mg} \times 100 \mathrm{~mL}^{-1}$ de peso fresco para melões cantaloupe contra $15,00 \mathrm{mg} \times 100 \mathrm{~mL}^{-1}$ nos melões "Honeydew". O conteúdo de vitamina C total aumenta com o desenvolvimento do fruto declinando durante o armazenamento. Menezes et al. (1998a) reportaram um acúmulo no conteúdo de vitamina $C$ total $20,63 \mathrm{mg} \times 100 \mathrm{~mL}^{-1}$ para $32,23 \mathrm{mg} \times 100 \mathrm{~g}^{-1}$ do melão tipo Galia Nun 1380.

O comportamento dos principais açúcares solúveis encontrados nestes genótipos (redutores, não-redutores e totais) está expresso na Figuras 5. Verificou-se comportamento diferenciado com redução no conteúdo de açúcares redutores no genótipo TSX 32096 de $5,34 \%$ para $3,21 \%$ do início ao final do experimento acompanhada por acúmulo nos açúcares não-redutores que variaram de $1,45 \%$ para $4,70 \%$. Entretanto, para o genótipo SUNEX 7057, foi observado acúmulo nos açúcares redutores (variação de $3,89 \%$ para $5,12 \%$ ) e decréscimo nos açucares não-redutores de $5,58 \%$ para $3,54 \%$. Como os açúcares redutores apresentam maior poder adoçante que a sacarose, pode-se inferir que houve aumento na qualidade organoléptica nos frutos do genótipo SUNEX 7057 durante o armazenamento até os 42 dias. A composição de açúcares solúveis totais do melão tem recebido considerável atenção em função da sua importância na determinação da qualidade. O conteúdo de açúcares solúveis totais encontrado neste experimento, que foi em média de $8,2 \%$ e $8,8 \%$, aos 42 dias de armazenamento, para os genótipos TSX 32096 e SUNEX 7057, nesta ordem, são semelhantes aos obtidos por Menezes et al., (1995) para AF 646.

Deste modo, pode-se concluir que os genótipos estudados conservam as suas características de qualidade por um período de até 42 dias de armazenamento sob condições ambiente, sem perdas significativas de suas propriedades 


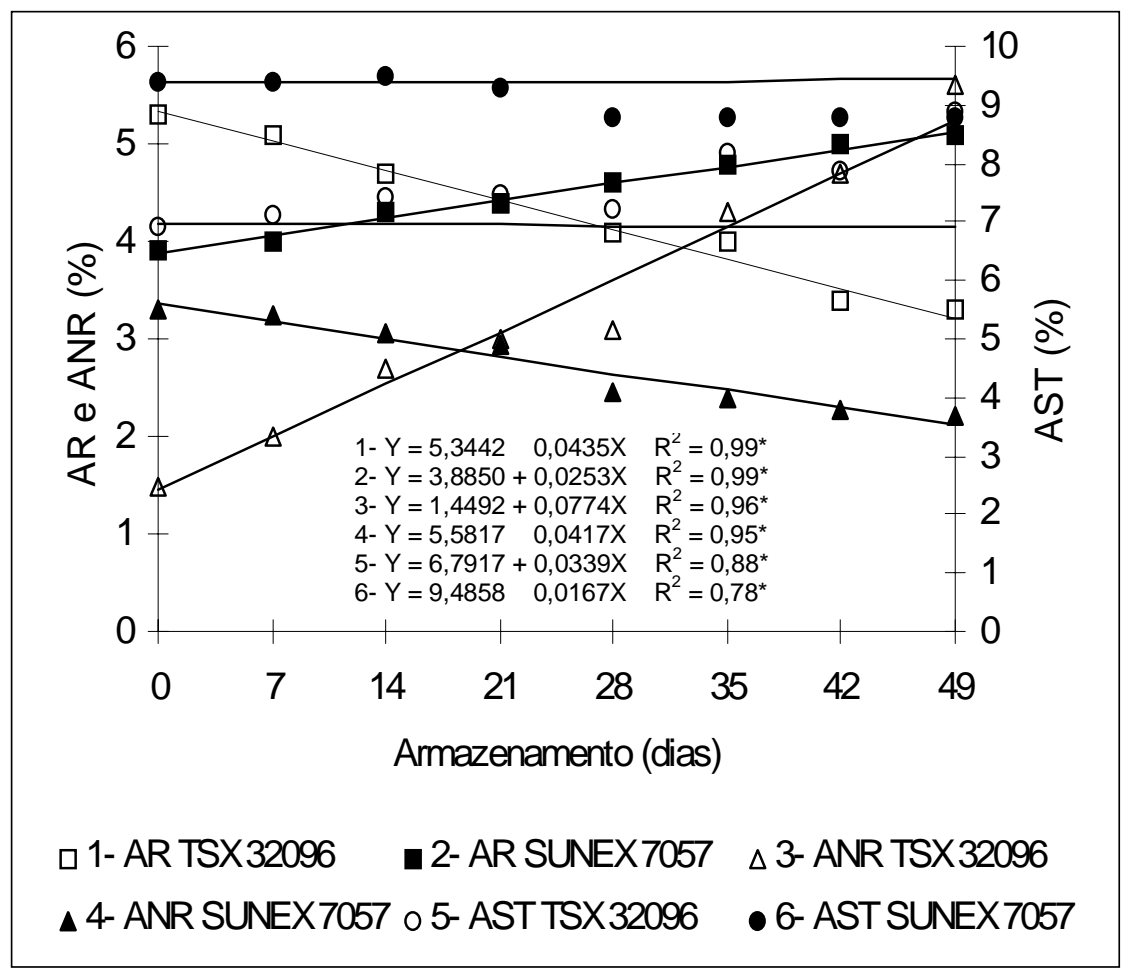

Figura 5. Efeito da duração do armazenamento em condições ambiente $\left(\mathrm{T}=30,0 \pm 1^{\circ} \mathrm{C}\right.$ e $\mathrm{UR}=50,0 \pm 5 \%$ ) sobre os açúcares redutores (AR), não-redutores (ANR) e totais (AST) de melão amarelo, genótipos TSX 32096 e SUNEX 7057. Mossoró, ESAM, 1998.

organolépticas, podendo ser comercializado em qualquer lugar do país, já que sua vida útil foi superior a 25 dias.

\section{AGRADECIMENTOS}

Os recursos desta pesquisa foram oriundos do convênio ESAM/ VALEFRUTAS/CNPq-BIOEX. Agradecemos também aos proprietários da Fazenda São João Ltda pela concessão dos frutos.

\section{LITERATURA CITADA}

ARTÉS, F.; ESCRICHE, A.J.; MARTINEZ, J.A.; MARIN, J.G. Quality factors in four varieties of melons (Cucumis melo, L.). Journal of Food Quality, v. 16, n. 2, p. 91-100, 1993.

AWAD, M. Fisiologia pós-colheita de frutos, São Paulo: Nobel, 1993, 114 p.

BARTLEY, L.M.; KNEE, M. The chemistry of textural changes in fruit during storage. Food Chemistry, v. 9, n. 7, p. 47 - 58, 1982.

CAMPBELL, C.A.; HUBER, D.J.; KOCH, K.E. Postharvest changes in sugars, acids, and color of carambola fruit at various temperatures. Hortscience, v. 24, n. 3, p. 472-475, 1989.

CARVALHO, H.A.; CHITARRA, M.I.F.; CHITARRA, A.B.; MENEZES, J.B. Vida útil pós-colheita de melão "Yellow King". Revista Brasileira de Fruticultura, Cruz das Almas, v. 17, n. 3, p. 111-118, 1995.
COHEN, R.A.; HICKS, J.R. Effect of storage on quality and sugars in muskmelon, Journal of the American Society for Horticultural Science, v. 111, n. 4, p. 553-557, 1986.

DHIMAN, J.S.; TARSEM, L.A.L.; BAJAJ, K.L. Evaluation of muskmelon (Cucumis melo L.) genotypes for multiple disease resistance, yield, and quality characterstics. Tropical Agriculture, v. 72, n. 1, p. 58-62, 1995.

DIAS, R.C.S.; COSTA, N.D.; CERDAN, C.; SILVA, P.C.G.; QUEIROZ, M.A.; ZUZA, F.; LEITE, L.A.S.; PESSOA, P.F.A.P.; TERAO, D.A. Cadeia produtiva do melão no Nordeste. In: CASTRO, A.M.G.; LIMA, S.M.V.; GOEDERT, W.J.; FILHO, A.F.; VASCONCELOS, J.R.P. Cadeias Produtivas e Sistemas Naturais: Prospeção Tecnológicas. SPI-Brasília. 1998. p. 440 - 493.

EITENMILLER, R. Nutrient composition of Red Delicious apples, peaches, Honey Dew melons, cantaloupes, Florida Pink and Texas ruby Red grapefruit, and Florida oranges. Athens: The university of Georgia, 1987. 15 p. (Research report 526).

EVENSEN, K.B. Effects of maturity at harvest, storage temperature and cultivar on muskmelon quality. Hortscience, v. 18, n. 6 , p. 907-908, 1983.

GONÇALVES, F.C.; MENEZES, J.B.; ALVES, R.E. Vida útil pós-colheita de melão "Piel de Sapo" armazenado em condição ambiente. Horticultura Brasileira, Brasília, v. 14, n. 1, p. 49-52, 1996.

GRANGEIRO, L.C. Densidade de plantio em híbridos de melão amarelo. Mossoró: ESAM, 1997. 48 p. (Tese mestrado).
INSTITUTO ADOLFO LUTZ. Normas Analíticas do Instituto Adolfo Lutz: métodos químicos e físicos para análise de alimentos, São Paulo. 1985, v. 1, p. 392 - 395

JANDEL SCIENTIFIC. User's Manual. Califórnia: Jandel Scientific, 1991. 280 p.

KADER, A.A., Postharvest biology and technology: an overview. In: KADER, A.A. Postharvest Technology of Horticultural Crops. California: University of California, p. 15-20, 1992.

KRAMER, A. Fruits and Vegetables. In: KRAMER, A.; TWIGG, B.A. Quality Control for the Food Industry. Connecticut: Avi Publishing Company, 1973. v 2, p. 157-227.

LESTER, G.E.; SHELLIE, K.C. Postharvest sensory and physiochemical attributes of Honey Dew melons fruit. Hortscience, v. 27, p. 1012 - 1014, 1992.

MENEZES, J.B.; CHITARRA, A.B.; CHITARRA, M.I.F.; BICALHO, U.O. Modificações dos componentes de parede celular de melão tipo Gália durante a maturação. Ciência e Tecnologia de Alimentos, Campinas, v. 17, n. 3, p. 301-308, Set. 1997.

MENEZES, J.B. Qualidade pós-colheita de melão tipo Galia durante a maturação $e$ o armazenamento. Lavras: UFLA, 1996. 157 p. (Tese doutorado).

MENEZES, J.B.; CASTRO, E.B.; PRAÇA, E.F; GRANGEIRO, L.C.; COSTA, L.B.A. Efeito do tempo de insolação pós-colheita sobre a qualidade do melão amarelo. Horticultura Brasileira, Brasília,. v. 16, n. 1, p. 80 - 81, 1998.

MENEZES, J.B.; CHITARRA, A.B ; CHITARRA, M.I.F.; BICALHO, U.O. Caracterização do melão tipo Galia durante a maturação. Horticultura Brasileira, Brasília, v. 16, n. 2, p. 159-164, 1998.

MENEZES, J.B.; CHITARRA, A.D.B.; CHITARRA, M.I.F.; CARVALHO, E.A. Caracterização pós-colheita do melão amarelo “Agroflora 646". Horticultura Brasileira, Brasília, v. 13, n. 2, p. 150-153, 1995.

MICCOLIS, V.; SALTVEIT Jr, M.E. Morphological and physiological changes during fruit growth and maturation of seven melon cultivars. Journal of the American Society for Horticultural Science, v. 116, p. 1025-1029, 1991.

MICCOLIS, V.; SALTVEIT, M.E. Influence of storage period and temperature on the postharvest characteristics of six melon (Cucumis melo L.), Inodorus Group) cultivars. Postharvest Biology and Technology, v. 5, p. 211-219, 1995.

MOTOMURA, Y. Formation of alcohol substances in muskmelon: variation among cultivarsand maturity. Scientia Horticulturae, v. 58, p. 343-350, 1994.

MUTTON, L.L.; CULLIS, B.R.; BLAKENEY, A.B. The objetive definition of eating quality in rockmelons (Cucumis melo L.). Journal Science Food Agricultural, v. 32, p. 385, 1981.

NORUSIS, M.J. SPSSPC statistics. Illinois: SPSS Inc., 1990.

PEDROSA, J.F. Cultura do melão. Mossoró: ESAM, 1997. 51 p. (Apostila).

SALUNKE, D.K.; DESAI, B.B. Postharvest biotecnology of vegetables. Flórida, CRC Press, v. 2, 1984, 194 p. 
Armazenamento de dois genótipos de melão amarelo sob condições ambiente.

SILVA, G.G. Armazenamento de melão, híbridos Gold Mine e Duna, sob condições ambiente. Mossoró: ESAM, 1993. 32 p. (Monografia graduação).

SOUTHGATE, D.A.T. Determination of foods carbohydrates, London: Elservier Applied Science, 1991, $232 \mathrm{p}$
SOUZA, M.C.; MENEZES, J.B.; ALVES, R.E. Tecnologia pós-colheita e produção de melão no Estado do Rio Grande do Norte. Horticultura Brasileira, Brasília, v. 12, n. 2, p. 188-190, 1994.

TUCKER, G.A. Intoducion. In: SEYMOUR, G.B.; TAYLOR, S.E.; TUCKER, G.A. Biochemistry of fruit ripening. London: Capman \& Hall, 1993. p. 255-266.
YAMAGUCHI, M.; HUGHES, D.L. YABUMOTO, K.; JENNINGS, W.G. Quality of canataloupe muskmelon: variability and attributes, Scientia Horticultural, v. 6, p. 59$70,1977$. 